\title{
QUANTITATIVE URINARY COPROPORPHYRIN EXCRETION AND ITS RELATION TO EDATHAMIL CALCIUM DISODIUM ADMINISTRATION IN CHILDREN WITH ACUTE LEAD INTOXICATION ${ }^{1,2}$
}

\author{
By J. JULIAN CHISOLM, JR. AND HAROLD E. HARRISON \\ (From the Department of Pediatrics, Johns Hopkins Hospital and School of Medicine and the \\ Pediatric Division of the Baltimore City Hospitals, Baltimore, Md.)
}

(Submitted for publication March 9, 1956; accepted June 29, 1956)

The disturbance of porphyrin synthesis induced by lead in both humans and experimental animals results in an increased excretion of porphyrins in the urine. The factors contributing to the porphyrinuria of lead poisoning remain incompletely understood. For the available evidence on the topic the reader is referred to several excellent reviews (1-4). Several groups of investigators (5-7), have reported data indicating a correlation between the concentration of coproporphyrin in urine and the concentrations of lead in the blood and urine of untreated industrial lead workers. These investigators used semiquantitative techniques for the estimation of coproporphyrin in urine. Bashour (8) has also reported a positive correlation $(r=0.37)$ between blood lead concentration and the quantitative excretion of coproporphyrin in the urine of lead-exposed adults.

During a study of acute and chronic lead poisoning in children certain quantitative relationships became apparent between the total daily urinary coproporphyrin output and a) the urine lead output induced by edathamil calcium disodium administration, ${ }^{8}$ and b) whole blood lead concentration.

\section{MATERIALS AND METHODS}

The data to be presented are based upon serial determinations of 24-hour urinary coproporphyrin output, 24hour urine lead output and whole blood lead concentra-

1 This work was supported by grants from the Division of Research Grants, National Institutes of Health, Department of Health, Education and Welfare (G-3918) and from the Lead Industries Association, New York, N. $Y$.

2 Read in part before the Combined Meeting of the American, British and Canadian Pediatric Societies, Quebec City, Quebec, June 1955.

3 Edathamil calcium disodium used during this study was kindly supplied by Riker Laboratories, Inc., Los Angeles, California. tions in children during and following their recovery from acute lead encephalopathy. All of these children were treated initially with one or two courses of edathamil calcium disodium, which chelates with lead and increases its excretion in the urine. The dosage used in all patients was $75 \mathrm{mg}$. per $\mathrm{Kg}$. per day, and this was given in divided doses subcutaneously or intramuscularly for periods of five to seven days with an interval of 14 to 21 days between courses. The criteria, upon which the diagnosis of acute lead encephalopathy was based, are reported in another paper (9). The subjects ranged in age from 18 months to $41 / 2$ years. Following recovery from their initial episode of encephalopathy none of the subjects included in the present report had any known reexposure to abnormal sources of lead.

Urinary coproporphyrin ${ }^{4}$ output was determined by the photofluorimetric technique of Schwartz, Zieve, and Watson (10). In this laboratory determinations of total urinary coproporphyrin output in control subjects gave values which agreed with the normal range for children reported by Hsia and Page (11) and Nevé and Aldrich (12) (0 to $75 \gamma$ per $24 \mathrm{hrs}$. for children weighing less than $80 \mathrm{lbs}$.). The age and weight distributions of the control subjects were comparable to those of the patients in the present study.

For the determination of lead in urine specimens were wet-digested and their lead content determined colorimetrically with dithizone according to the method of Bessman and Layne (13).

Twenty-four hour urine collections were carried out on a metabolism frame (14) with precautions for the separation of urine and feces. Lead-free collection apparatus was used throughout. When specimens for coproporphyrin analysis were collected, 1 to 3 grams of sodium carbonate, reagent grade, were added to the collection bottle as preservative. Five-gram samples of the lot of sodium carbonate used contained no detectable quantity of lead. Daily urinary creatinine excretion was determined as a further check on the completeness of each urine collection.

Whole blood lead concentration was determined by the Division of Laboratories of the Baltimore City Health Department by a wet-digestion dithizone technique (15).

\footnotetext{
4 The authors wish to thank Dr. Samuel Schwartz for his generous gift of coproporphyrin which was used as a reference standard.
} 
Specimens of blood were collected with the lead-free apparatus supplied by that laboratory.

\section{RESULTS}

In children with lead intoxication a positive correlation is found between the 24-hour urinary coproporphyrin output just prior to the parenteral administration of edathamil calcium disodium and the lead output during the first 24-hour period following institution of treatment with this chelating agent. The relationship is an exponential one and is shown graphically in Figure 1 . In this diagram the urinary coproporphyrin output is plotted logarithmically on the ordinate against the arithmetic plot of urine lead output on the abscissa so that a straight line is obtained. The slope of this regression (b) is 0.1275 ; its correlation coefficient $(r=0.8213)$ is statistically significant $(P<$ 0.03 ) when $N=7$. Since treatment with edathamil calcium disodium could not be deferred initially in patients with acute lead encephalopathy in order to obtain pre-treatment urinary coproporphyrin values, the data shown in Figure 1 were obtained from patients during the recovery phase. Each point on the curve was obtained from a different patient. Two of the patients had had acute lead encephalopathy one year previously and were clinically asymptomatic. In the remaining five the determinations were made two to three weeks after hospital admission and the initial

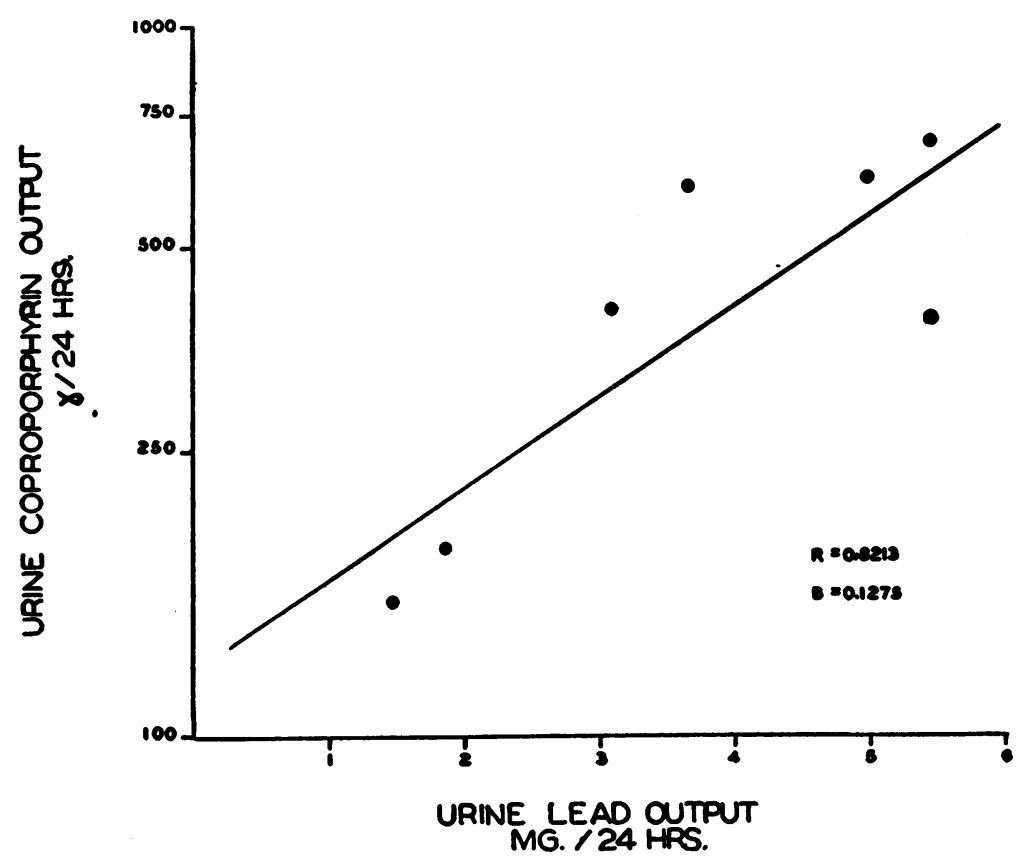

Fig. 1. Relation Between Pre-Treatment Urine Coproporphyrin Output and Urine Lead Output During First 24 Hours of EdathamiL Calctum Disodium Administration

In this graph the urine lead (mg. per $24 \mathrm{hrs}$ ) is the quantity excreted during the first 24 hours following parenteral administration of edathamil calcium disodium; whereas, the urine coproporphyrin ( $\gamma$ per $24 \mathrm{hrs}$.) is that determined just prior to institution of therapy. Urine lead output is plotted arithmetically on the abscissa and urine coproporphyrin output on the ordinate on a logarithmic scale. The relationship can be expressed mathematically by the following equation:

$$
\log \mathrm{y}=\log \mathrm{a}+\mathrm{b} \mathbf{x} \text {. }
$$

In this equation $y=$ urine coproporphyrin output ( $\gamma$ per 24 hrs.) ; $a=$ intercept of $y$ on its axis; $b=$ regression coefficient ; and $x=$ urine lead output (mg. per 24 hrs.).For this regression $b=0.1275$ and the correlation coefficient $r=0.8213$ for which $\mathrm{P}<0.03$ but $>0.02$ when $\mathrm{N}-2=5$. 


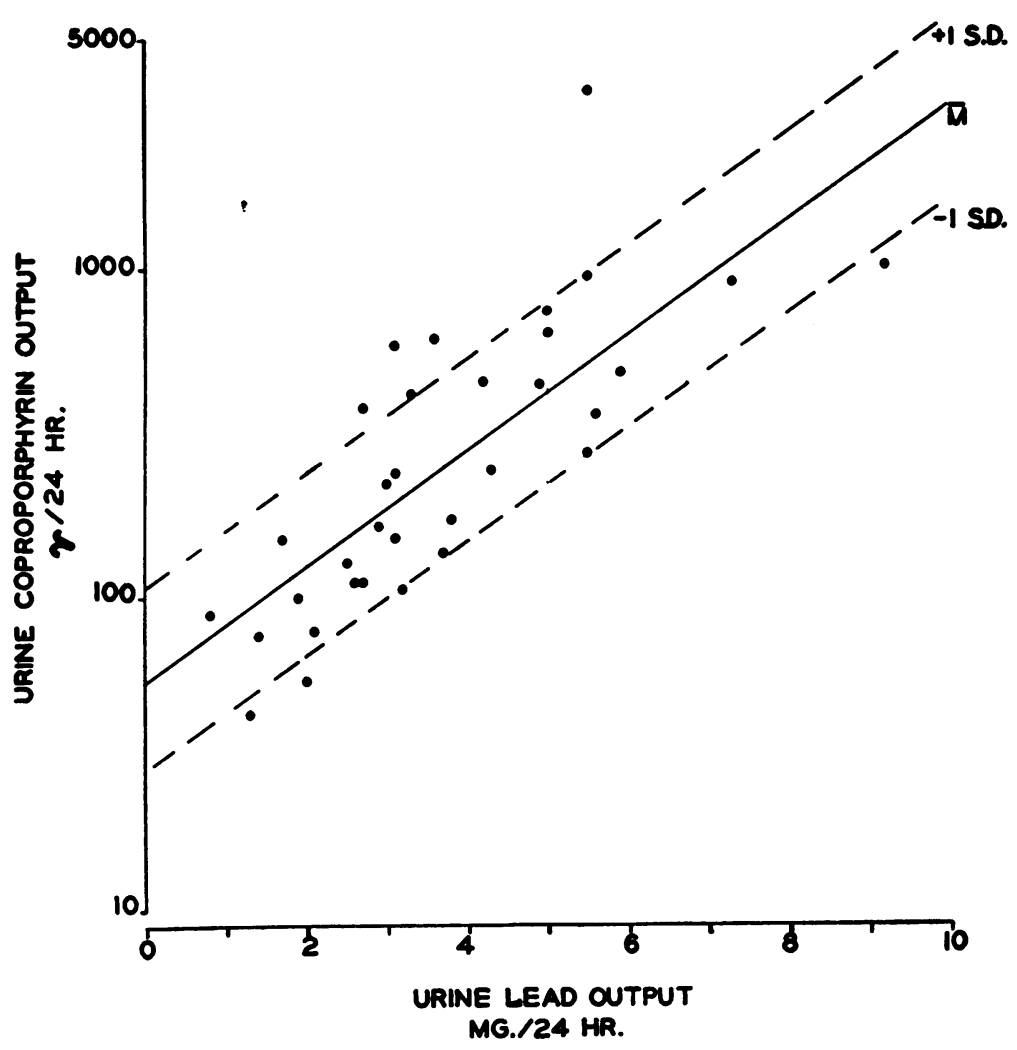

Fig. 2. Relation Between Simultaneous Urinary Excretion of lead and Coproporphyrin During Edathamil Calcium Disodium Administration

In this figure the urine lead output (mg. per $24 \mathrm{hrs}$.) during edathamil calcium disodium treatment is plotted on the abscissa against urinary coproporphyrin output ( $\gamma$ per 24 hrs.) on the ordinate on a logarithmic scale. Each point represents a single day's excretion. The mathematical relationship is the same as that indicated for the relationship depicted in Figure 1. For the relationship shown above, the mean regression line is drawn as a solid line and \pm 1 S.D. of $y$ on $x$ as interrupted lines.

$$
\text { For this regression: } \begin{aligned}
: b & =0.1762 \\
r & =0.7642(P<0.001) \\
N & =33
\end{aligned}
$$

treatment of acute lead encephalopathy. The coproporphyrin determinations were made on 24-hour urine samples obtained one to three days prior to the institution of a course of edathamil calcium disodium treatment. This was done in order that any possible effect of the drug upon urinary porphyrin excretion independent of its effect upon lead metabolism might be eliminated.

A similar correlation is also found between the simultaneous urinary excretion of coproporphyrin and of lead during the parenteral administration of edathamil calcium disodium. This is shown in Figure 2. This correlation is demonstrable both during the acute and convalescent phases of lead encephalopathy if patients with marked oliguria during the acute illness are excluded. The relationship is again an exponential one. The data plotted in Figure 2 were computed from 33 simultaneous determinations of lead and coproporphyrin in urine during 14 courses of therapy in nine patients. The slope of this regression (b) is 0.1762 ; the correlation coefficient $(r=0.7642)$ is statistically highly significant $(\mathrm{P}<0.001)$.

In Table I are shown the changes in the excretion of coproporphyrin and lead in the urine of children with lead poisoning during the adminis- 
tration of edathamil calcium disodium. During the period of treatment the urinary coproporphyrin excretion usually decreases rapidly and approaches the normal range by the fourth to sixth day. Likewise, the daily urine lead output also decreases; but at a lesser rate. Upon cessation of treatment, however, urinary coproporphyrin excretion frequently returns to amounts approaching the high pre-treatment levels. Our data indicate that a new relatively steady state, as measured by coproporphyrin excretion, is reached on the average 14 to 21 days after discontinuance of drug therapy.

At and after this time a positive exponential relationship between urinary coproporphyrin output and whole blood lead concentration is found, as is indicated in Figure 3. The slope of the regression between these two values is 0.1850 , when urine coproporphyrin output is plotted logarithmically and whole blood lead concentration arithmetically. The correlation coefficient of the regression $(r=0.6642)$ is highly significant $(P<$
0.001 ). The data were computed from 70 simultaneous, paired determinations in 15 patients who were studied during the first year after their recovery from an episode of acute lead encephalopathy. In this group of patients there was no known reexposure to lead after their initial hospitalization. The relationship shown in Figure 3 could not be demonstrated in children during the first two to three weeks following hospitalization for treatment of acute lead encephalopathy. During this period whole blood lead concentrations decrease rapidly from the very high levels initially present.

In children convalescent from acute lead poisoning this relationship between urine porphyrin excretion and blood lead concentration was also disturbed by intercurrent acute infections, during which sharp increases in urine coproporphyrin excretion were observed. In three of five convalescent patients, who were studied during such illnesses, the previously normal or slightly elevated

TABLE I

Output of lead and coproporphyrin in urine during edathamil calcium disodium administration *

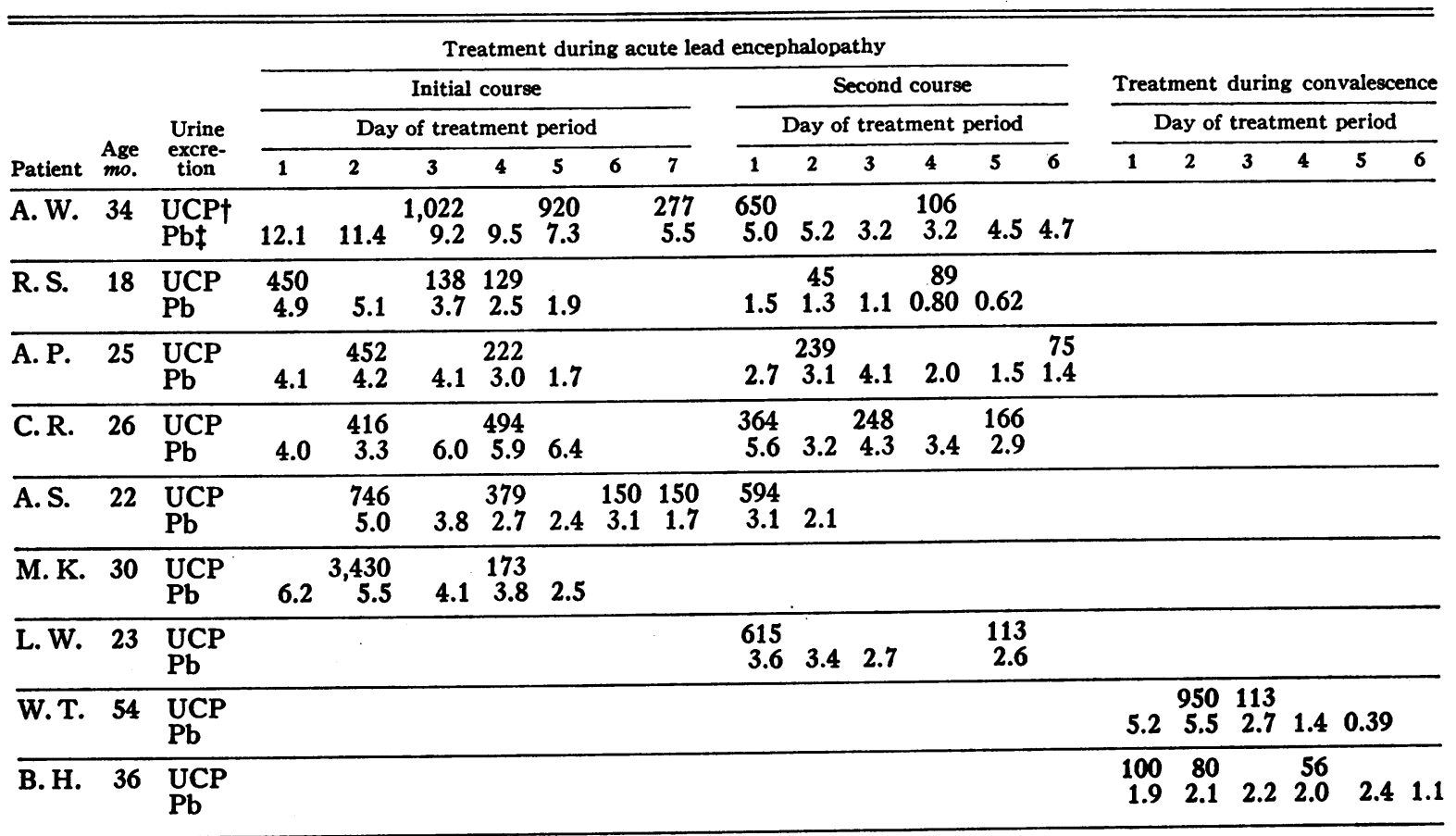

† Urine coproporphyrin $=\gamma / 24$ hrs.

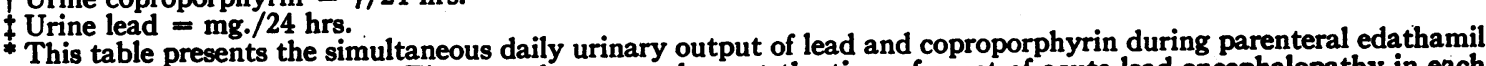
calcium disodium administration. The ages shown are those at the time of onset of acute lead encephalopathy in each patient. "Initial Course" refers to treatment instituted at the time of onset of encephalopathy. "Second Course" refers to treatment begun 14-21 days after the "initial course." Patients B. H. and W. T. received treatment 10 months and 12 months, respectively, after onset of acute lead encephalopathy. 


\section{RELATION DETWEEN URINE COPROPOAPHYRIN OUTPUT AND BLOOD LEAD CONCENTRATION}

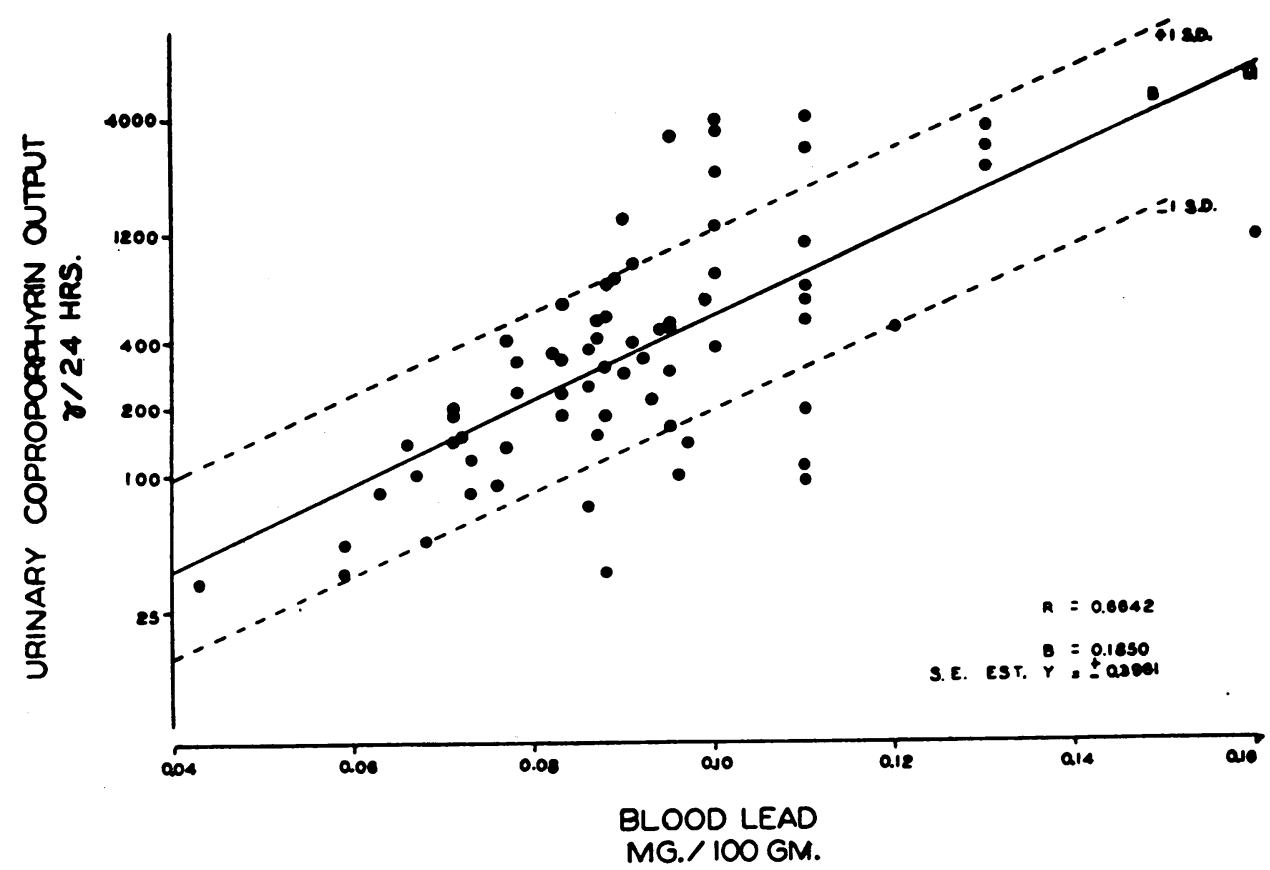

Figure 3

The data shown in the graph are based upon 70 simultaneous determinations of whole blood lead concentration and $24 \mathrm{hr}$. urinary coproporphyrin output in 15 patients made two weeks or longer after completion of edathamil calcium disodium administration. These data were obtained in patients in whom there was no known reexposure to lead following the initial illness. Whole blood lead concentration (mg. $\mathrm{Pb}$ per $100 \mathrm{gm}$. whole blood) is plotted arithmetically on the abscissa against the urinary coproporphyrin output ( $\gamma$ per $24 \mathrm{hrs}$.) which is plotted on the ordinate on a logarithmic scale. The mean regression line is shown as a solid line; while \pm 1 S.D. of $\mathbf{y}$ on $\mathbf{x}$ from this mean regression is indicated by the broken lines.

$$
\text { For this regression: } \begin{aligned}
b & =0.1850 \\
r & =0.6642(P<0.001) \\
N & =70
\end{aligned}
$$

coproporphyrin outputs rose to levels of 500 to $1,000 \gamma$ per $24 \mathrm{hrs}$. during the infection. Their blood lead concentrations remained unchanged in the range of 0.05 to $0.075 \mathrm{mg}$. lead per $100 \mathrm{gm}$. of whole blood. In the absence of infection in convalescent lead-poisoned patients this range of whole blood lead concentration is not ordinarily associated with increases in urinary coproporphyrin output above $150 \gamma$ per $24 \mathrm{hrs}$.

\section{DISCUSSION}

The present studies in children with lead poisoning demonstrate a positive exponential correlation between daily total urinary coproporphyrin excretion and that quantity of lead in the body which is available for chelation and urinary excretion under the influence of edathamil calcium disodium (Figures 1 and 2). Foreman and Trujillo (16) have shown in humans that edathamil calcium disodium rapidly diffuses into all tissues with the exception of the erythrocytes and spinal fluid. The data of Rubin (17) indicate that in experimental animals this chelating agent removes lead primarily from non-skeletal tissues and enhances its excretion in urine and its storage in cancellous bone. It seems reasonable to assume, therefore, that the initial output of lead in the urine following edathamil calcium disodium administra- 
tion represents rapidly mobilizable tissue lead. The total urinary porphyrin output is then probably correlated with the concentration of lead in the various soft tissues of lead-poisoned individuals. If this be the case, the quantitative coproporphyrin output can be considered to provide a measure of the "metabolically active" portion of lead responsible for its toxic effects.

The postulation that coproporphyrinuria in plumbism is quantitatively related to the soft tissue concentrations of lead and, therefore, to the toxic fraction of body lead is supported by the following observations. From data reported by Aub, Fairhall, Minot, and Reznikoff (18), by Kehoe, Thamann, and Cholak (19), and by ourselves (9) it can be estimated that the total lead content of the non-skeletal tissues may vary between 20 and 100 mg. $\mathrm{Pb}$ in children dying from acute lead encephalopathy. The data presented in Table I indicate that, under the influence of edathamil calcium disodium, the urinary coproporphyrin output does not approach normal levels in acutely ill patients until the latter days of drug administration, when the cumulative urinary excretion of lead reaches 20 to $50 \mathrm{mg}$. It was also observed clinically in the majority of acute cases of severe encephalopathy that subsidence of coma, convulsions and increased intracranial pressure usually occurred on the second or third day after institution of therapy. In individual patients the subsidence of these symptoms roughly coincided, during their initial course of treatment, with the time at which the urinary coproporphyrin excretion decreased.

In many patients with acute lead poisoning the urinary coproporphyrin output rises again to abnormal levels within a few days after cessation of drug administration. There are two possible interpretations. The edathamil calcium disodium present in the tissues may chelate enough of the remaining tissue lead to restore more normal biochemical pathways in pyrrole metabolism. Because of the rapid urinary excretion of this compound it disappears from the body within a few days. The degree of coproporphyrinuria reappearing at this time might then be a reflection of the residual soft tissue lead concentration which is no longer inactivated by combination with the chelating agent. In such patients subsequent administration of edathamil calcium disodium results again in an increased urinary excretion of lead, the magnitude of which can be predicted by the data in Figure 1. On the other hand, the reduction in coproporphyrin excretion which occurs after five to seven days of edathamil calcium disodium administration might be in part due to direct interference by this chelating agent with the synthesis of porphyrins. It has been reported by Gibson, Neuberger, and Scott (20) that deltaaminolevulinic acid dehydrase is widely distributed in the tissues. This enzyme converts delta-aminolevulinic acid to porphobilinogen, the precursor of the known biologically important porphyrins. These workers found that edathamil inhibits the activity of delta-aminolevulinic acid dehydrase in vitro to a greater extent than does lead.

In the convalescent phase of lead poisoning when lead is redistributed among the various tissues and a new, relatively stable, metabolic state has been achieved, the exponential relationship between blood lead concentration and urinary coproporphyrin output shown in Figure 3 can be demonstrated. This finding confirms the correlation found in adult industrial lead workers between blood lead concentration and urinary coproporphyrin excretion reported by Shiels, Palmer, Cornish, and Kearley (7) and Bashour (8). A rather large variation in whole blood lead concentration with respect to urinary coproporphyrin output can be noted in Figure 3. In part, the magnitude of this variation may be explained by the fact that most of the data in Figure 3 were obtained during the first three to six months of convalescence at a time when hemoglobin and hematocrit values were rising rapidly. The resultant variations in total erythrocyte mass may have had an appreciable effect upon whole blood lead concentrations, since in latent lead poisoning approximately 95 per cent of the whole blood lead may be found in the erythrocytes. The magnitude of these variations suggests that the total daily urinary porphyrin excretion reflects more closely the concentration of the "metabolically active" fraction of lead in the tissues responsible for the toxic manifestations than does the whole blood lead concentration. This is particularly pertinent when whole blood lead concentration lies in the range, 0.075 to $0.10 \mathrm{mg}$. per $100 \mathrm{gm}$. whole blood, which represents only a moderate increase above the normal value. It is in this range of blood lead concentration that urinary coproporphyrin 
excretion may be most useful as a measure of "metabolically active" lead in the body and of the efficacy of treatment of lead poisoning by chelating agents.

The sharp rise in urinary coproporphyrin excretion without concomitant change in whole blood lead concentration seen in convalescing patients during intercurrent acute infections is of interest in view of the clinical observation that such infections have frequently been accompanied by a recrudescence of the clinical manifestations of lead poisoning. Studies (21) in adults without known lead exposure indicate that a two to three-fold increase in urinary coproporphyrin output may occur in chronic bacterial infections. The five to sixfold increments in urinary coproporphyrin output in three of five children with intercurrent infections offer biochemical support to the clinical observation that such infections may intensify the toxic effects of lead in children during the early months of convalescence from acute lead intoxication. When this occurs additional treatment with chelating agents is probably both indicated and efficacious.

Lastly, it should be noted that the method of Schwartz, Zieve, and Watson (10) used for porphyrin analysis in this study measures total urinary coproporphyrin. As pointed out by these authors (22) and confirmed by Comfort, Moore, and Weatherall (23) this method includes the determination not only of pre-formed coproporphyrin but also of significant amounts of an, as yet, unidentified precursor (or precursors) which is quantitatively converted to coproporphyrin during the analysis. Indeed, from his studies Weatherall (24) has suggested that a large portion of the urinary coproporphyrin measured may actually be excreted as precursor. The determination of total coproporphyrin in urine does appear, however, to be a useful measure of "chelatable" lead in the tissues, although preformed coproporphyrin may not be the principle metabolite excreted in the urine in lead poisoning.

\section{SUMMARY AND CONCLUSIONS}

In children with lead poisoning a positive correlation has been demonstrated between the urine lead output during the first day following the parenteral administration of edathamil calcium di- sodium and the total daily urinary coproporphyrin output just prior to the administration of the chelating agent. This relationship is an exponential one and was demonstrated in both the early recovery phase and the chronic phase of plumbism.

A similar correlation was found between the simultaneous daily urinary excretion of coproporphyrin and lead during parenteral edathamil calcium disodium administration.

During the convalescent phase in children who had recovered from acute lead encephalopathy an exponential relation was also found between the whole blood lead concentration and total daily urinary coproporphyrin excretion. This relationship could not be shown during the initial acute phase of encephalopathy when whole blood lead concentration was frequently quite high and decreasing rapidly.

These data indicate that the urinary coproporphyrin output is related to that fraction of lead in the tissues which is available for chelation and urinary excretion under the influence of edathamil calcium disodium. From the urinary coproporphyrin output one can predict the magnitude of lead output in the urine which will follow the parenteral administration of edathamil calcium disodium. Since it is believed that this chelating agent initially removes lead primarily from nonskeletal tissues, it appears reasonable to propose that the urinary coproporphyrin output in children with plumbism is correlated with the concentration of lead in soft tissues. Hence, the urinary coproporphyrin excretion provides a sensitive biochemical index of "metabolically active" and presumably toxic lead in tissues.

\section{ACKNOWLEDGMENTS}

The authors wish to express their appreciation to Dr. Emanuel Kaplan of the Baltimore City Health Department, in whose laboratory all of the blood lead determinations reported in this study were performed. Invaluable technical assistance was rendered by $\mathrm{Mr}$. Peter Wei and Mr. David Krogmann.

\section{REFERENCES}

1. Watson, C. J., and Larson, E. A., The urinary coproporphyrins in health and disease. Physiol. Rev., 1947, 27, 478.

2. Aldrich, R. A., Labbe, R. F., and Talman, Ellen L., A review of porphyrin metabolism with special reference to childhood. Am. J. M. Sc., 1955, 230, 675. 
3. Vanotti, A., Porphyrins: Their Biological and Chemical Importance. Translated by C. Rimington, London, Hilger and Watts, Ltd., 1954.

4. Watson, C. J., Porphyria. Advances in Int. Med., 1954, 6, 235.

5. de Langen, C. D., and ten Berg, J. A. G., Porphyrin in the urine as a first symptom of leadpoisoning. Acta med. Scandinav., 1948, 130, 37.

6. Maloof, C. C., Role of porphyrins in occupational diseases. I. Significance of coproporphyrinuria in lead workers. Arch. Indust. Hyg., 1950, 1, 296.

7. Shiels, D. O., Palmer, G. R., Cornish, P. E., and Kearley, E. J., Porphyrinuria in persons exposed to lead hazards. M. J. Australia, 1953, 2, 171.

8. Bashour, F. A., Urinary uroporphyrin, porphobilinogen and coproporphyrin excretion in lead-exposed workers. J. Lab. \& Clin. Med., 1954, 44, 764.

9. Chisolm, J. J., Jr., and Harrison, H. E., The exposure of children to lead. Pediatrics, in press.

10. Schwartz, S., Zieve, L., and Watson, C. J., An improved method for the determination of urinary coproporphyrin and an evaluation of factors influencing the analysis. J. Lab. \& Clin. Med., 1951, 37, 843.

11. Hsia, D. Y.-Y., and Page, M., Coproporphyrin studies in children. I. Urinary coproporphyrin excretion in normal children. Proc. Soc. Exper. Biol. \& Med., 1954, 85, 86.

12. Nevé, R. A., and Aldrich, R. A., Porphyrin metabolism. III. Urinary and erythrocyte porphyrin in children with acute rheumatic fever. Pediatrics, 1955, 15, 553.

13. Bessman, S. P., and Layne, E. C., Jr., A rapid procedure for the determination of lead in blood or urine in the presence of organic chelating agents. J. Lab. \& Clin. Med., 1955, 45, 159.
14. Newberry, E., and Van Wyk, J. J., A technique for quantitative urine collection in the metabolic study of infants and young children. Pediatrics, 1955, 16, 667.

15. Kaplan, E., Personal communication.

16. Foreman, H., and Trujillo, T. T., The metabolism of $\mathrm{C}^{14}$ labeled ethylenediaminetetraacetic acid in human beings. J. Lab. \& Clin. Med., 1954, 43, 566.

17. Rubin, M., in Use of calcium ethylenediaminetetraacetate in treating heavy-metal poisoning. Report of a Conference held at Massachusetts General Hospital. Arch. Indust. Hyg., 1953, 7, 142.

18. Aub, J. C., Fairhall, L. T., Minot, A. S., and Reznikoff, P., Lead Poisoning. Baltimore, Williams and Wilkins Co., 1926, p. 71.

19. Kehoe, R. A., Thamann, F., and Cholak, J., Lead absorption and excretion in relation to the diagnosis of lead poisoning. J. Indust. Hyg., 1933, 15, 320.

20. Gibson, K. D., Neuberger, A., and Scott, J. J., The purification and properties of $\delta$-aminolaevulic acid dehydrase. Biochem. J., 1955, 61, 618.

21. Cartwright, G. E., Lauritsen, M. A., Jones, P. J., Merrill, I. M., and Wintrobe, M. M., The anemia of infection. I. Hypoferremia, hypercupremia, and alterations in porphyrin metabolism in patients. J. Clin. Invest., 1946, 25, 65.

22. Watson, C. J., Pimenta de Mello, R., Schwartz, S., Hawkinson, V. E., and Bossenmaier, I., Porphyrin chromogens or precursors in urine, blood, bile, and feces. J. Lab. \& Clin. Med., 1951, 37, 831.

23. Comfort, A., Moore, H., and Weatherall, M., Normal human urinary porphyrins. Biochem. J., 1954, 58, 177.

24. Weatherall, M., The fate of intravenously administered coproporphyrin III in normal and lead-treated rabbits. Biochem. J., 1952, 52, 683. 